Revista de la red interuniversitaria de estudios sobre las literaturas rioplatenses contemporáneas en Francia

\title{
Entre la Novela y el periódico obrero; entre Ongaro y Perón. Walsh y el semanario CGT (1968-1969)
}

Mariano Mestman

\section{OpenEdition}

Journals

Edición electrónica

URL: http://journals.openedition.org/lirico/3014

DOI: 10.4000/lirico.3014

ISSN: 2262-8339

Editor

Réseau interuniversitaire d'étude des littératures contemporaines du Río de la Plata

Referencia electrónica

Mariano Mestman, «Entre la Novela y el periódico obrero; entre Ongaro y Perón. Walsh y el semanario CGT (1968-1969) », Cuadernos LIRICO [En línea], 15 | 2016, Puesto en línea el 05 octubre 2016, consultado el 19 abril 2019. URL : http://journals.openedition.org/lirico/3014 ; DOI : 10.4000/ lirico.3014

Este documento fue generado automáticamente el 19 abril 2019.

\section{$\Theta \Theta \Theta \Theta$}

Cuadernos LIRICO está distribuido bajo una Licencia Creative Commons Atribución-NoComercialSinDerivar 4.0 Internacional. 


\title{
Entre la Novela y el periódico obrero; entre Ongaro y Perón. Walsh y el semanario CGT (1968-1969)
}

\author{
Mariano Mestman
}

A Lilia Ferreyra (1944-2015),

la primera que me contó esta historia.

1 La experiencia en el semanario CGT, y por extensión con la CGT de los Argentinos, ocupan un lugar no menor en la trayectoria de Rodolfo Walsh¹. A partir de allí, desplaza sus proyectos literarios en pos de una dedicación plena a proyectos político revolucionarios, muchas veces, como en este caso, protagonizando iniciativas periodísticas, comunicacionales. Este desplazamiento tiene una manifestación precisa durante 1968 en el abandono de la escritura de una novela que debía estar lista para fines de ese año ${ }^{2}$, por haberse dedicado a la fundación y dirección del semanario, tarea por la que ni él ni ninguno de los redactores cobraba un centavo.

El 28 de enero de 1969, en sus «papeles personales», el escritor se refiere a esta y otras cuestiones políticas o de supervivencia material que lo muestran intranquilo, dubitativo:

Mañana tengo que ir a hablar con Pedro y según todas las apariencias habré de conchabarme por primera vez en diez años. La anterior fue en PL (Prensa Latina).

La decisión parece inevitable por el grado de deterioro económico a que he llegado, y la falta de otra salida equivalente.

Mi deuda con (el editor) Jorge Álvarez alcanza en este momento a 2.250 dólares, es decir, 797.500 pesos. Con eso he vivido desde octubre de 1967 hasta hoy, a razón de 150 dólares mensuales.

El arreglo con él preveía una novela que podía estar lista de octubre a diciembre de 1968, y de la que apenas tengo escritas unas treinta páginas [...]

El tiempo que debí dedicar a la novela lo dediqué, en gran parte, a fundar y dirigir el semanario de la CGT.

Jorge Álvarez tendría, pues, en este momento, el derecho a decir que lo he estafado. Eso desde luego me preocupa sin que -por otra parte- me sienta convencido de haber obrado mal.

La estafa por otra parte, no es excesiva. Le entregué dos libros -una antología cubana y la reedición de Operación Masacre-, que si vendieran entre los dos 10.000 
ejemplares a 400 pesos, saldarían la mitad de la deuda. Un tercer libro sobre el caso Rosendo la reduciría quizá a 300.000 pesos $^{3 .}$ [...]

En Panorama me ofrecen 140.000 pesos mensuales.

La deuda con Álvarez quedaría como caución de la novela que, a pesar de todo, debo escribir.

La novela. El desenlace de esta situación no me toma totalmente de sorpresa. A partir de setiembre $u$ octubre intenté sumergirme en la novela y descontar el tiempo perdido. Me encontré entonces con dos cosas. Una, que el tiempo me rendía mucho menos de lo habitual. Lo ocurrido este mes es característico: en treinta horas efectivas trabajadas, he escrito alrededor de cinco páginas. El segundo hecho es que el trabajo, inicialmente febril, en CGT, me fatigó mucho, y a esa fatiga se sumó el desaliento por la momentánea derrota de Ongaro. [...]

La crisis ideológica. En 1968 he actuado mucho más en función política que anteriormente, incluso que en Cuba. Quiero decir, con muchas menos dudas, y con una conciencia más clara.

No por eso el qué hacer se ha presentado en forma menos acuciante. Al contrario. Mi reingreso en la órbita del marxismo ha puesto al día todas las llagas de la conciencia. La disyuntiva entre el trabajo agitativo del semanario, y el sinuoso, paciente, elaborado de la literatura se presentó con caracteres graves, que no he superado. Ahora mismo, vgr., fantaseo que la Novela es el último avatar de mi personalidad burguesa, al mismo tiempo que el propio género es la última forma de arte burgués, en transición a otra etapa en que lo documental recupera su primacía. Pero tampoco estoy seguro de esto, que puede ser una excusa de mi momentáneo fracaso. ${ }^{4}$

3 La extensa cita de estas líneas se justifica en la medida en que, escritas a inicios de ese año crucial que fue 1969, condensan un proceso atravesado por una serie de dudas e incertidumbres, y cuya «resolución» es más práctica que producto de una elaboración conceptual sobre el problema del compromiso intelectual ${ }^{5}$. Este trabajo busca recuperar el lugar clave que el semanario CGT ocupó en ese proceso, una experiencia ya reconocida pero, entiendo, no suficientemente estudiada.

4 Las inquietudes de Walsh respecto del escaso tiempo para compatibilizar el proyecto político y el literario, o sobre el tipo de literatura a desarrollar, atraviesan sus escritos personales a lo largo de 1968/1969 y en los años inmediatos posteriores, ya que, «a pesar de todo», consideraba que debía escribir la novela ${ }^{6}$, claro que incorporando la experiencia del semanario, incluso «no como tema, sino como visión del mundo» ${ }^{7}$, o hechos de la coyuntura histórica como el Cordobazo y el Rosariazo: «Los hechos producidos en Córdoba y Rosario proveen a la novela de un nuevo "centro" de verdad. Ya no es preciso remontarse al año 19, sino a lo que ha pasado en estos días, a la gente que uno conoce. Cuando cuarenta mil hombres y mujeres salen a la calle, como en Córdoba, un héroe es cualquiera» ${ }^{8}$.

«Un héroe es cualquiera». También en esos años, Walsh se refirió al riesgo político de delegar en héroes individuales procesos de transformación necesariamente colectivos. En la famosa entrevista que le realizara Ricardo Piglia en 1970, y a propósito de su cuento «Un oscuro día de justicia» que había terminado de escribir un mes después de la muerte de Ernesto Guevara (octubre 1967), Walsh recuperaba las referencias del texto al aprendizaje final del «pueblo» respecto de encontrarse solo y de la consecuente necesidad de pelear por sí mismo contra las expectativas de salvación depositadas en «héroes externos». Y consideraba que se trataba de una posición aplicable a la situación argentina, sea al peronismo o a las expectativas despertadas por figuras como el che, como se expresaba -recordaba- en el lamento después de su muerte y la consideración de que si estuviese vivo todos se comprometerían con su causa. «Concepto totalmente místico - 
afirmaba Walsh-, es decir, el mito, la persona, el héroe haciendo la revolución en vez de ser el conjunto del pueblo cuya mejor expresión es sin duda el héroe, en este caso el Che Guevara, pero [...] ningún tipo aislado por grande que sea puede absolutamente hacer nada»". Ante esto, la propuesta de búsqueda de un «héroe colectivo», el pueblo, que de algún modo el escritor y periodista venía delineando en los dos años inmediatamente anteriores desde las páginas del semanario $C G T^{10}$.

Interesa destacar ese momento (1968-1969) justamente por esa búsqueda, pero también porque resulta representativo respecto de otras intervenciones de sujetos o formaciones culturales e intelectuales. Sobre esto volveré al final.

\section{Semanario CGT}

6 A fines de marzo de 1968, el Congreso Normalizador de la CGT (llamado «Amado Olmos» en homenaje a este dirigente fallecido poco antes en un accidente automovilístico) consagró como secretario general de la luego denominada CGT de los Argentinos (CGTA) a Raimundo Ongaro, representante de los sectores combativos del sindicalismo peronista. Al mismo tiempo, allí cristalizó una nueva división en el movimiento obrero producto del alejamiento de los gremios adheridos al vandorismo, que conformaron la CGT Azopardo, y aquellos de la corriente participacionista, más cercana al régimen militar de Juan Carlos Onganía, instaurado en 1966.

Un mes después del Congreso Normalizador aparecería el semanario CGT, en tanto órgano oficial de la central obrera. Realizado por un grupo de periodistas nucleado en torno a Walsh, acompañó la experiencia político-sindical en los años sucesivos, difundiendo los ejes de su Programa, muchos de los cuales poco después se generalizarían en consignas obreras y populares durante el período de «lucha de calles» abierto por el Cordobazo y otras revueltas de mediados de $1969^{11}$. Un período de confrontación que venía gestándose desde algunos años antes con la constitución de un tejido social y lazos de solidaridad que le dieron sustento, y que la CGT de los Argentinos (CGTA) también contribuyó a desarrollar.

El carácter pluralista y frentista del proyecto de la CGTA, su oposición activa y abierta al régimen militar, se expresó rápidamente con la convocatoria a actos y movilizaciones en todo el país el $1^{\circ}$ Mayo de 1968. En la medida en que el interior comenzaba a constituirse en uno de los sostenes principales de la nueva central obrera, Ongaro viajó para participar de los actos en Córdoba, donde Agustín Tosco y el gremio de Luz y Fuerza regional trabajaban activamente el apoyo a la nueva CGT ${ }^{12}$. Allí expuso el «Mensaje del $1^{\circ}$ de Mayo», elaborado junto a Rodolfo Walsh, constituido en Programa de la CGTA.

Los responsables del periódico por el Consejo Directivo fueron Ongaro y el dirigente naval Ricardo de Luca, secretario de Prensa, y su dirección quedó en manos de Walsh, quien convocó a Rogelio García Lupo, Horacio Verbitsky, y un equipo de periodistas. Funcionando en la sede del gremio Gráfico de la calle Paseo Colón en la Capital, el periódico se editó semanalmente durante 1968, quincenalmente entre enero y junio de 1969, mensualmente desde allí, con el inicio de la etapa clandestina, hasta febrero de 1970 13.

El «Programa del $1^{\circ}$ de Mayo» tiene todas las características del Manifiesto político ${ }^{14}$, y funcionó como una suerte «de matriz» a partir de la cual se elaboró el periódico ${ }^{15}$. Es decir, la denuncia de la situación del país en todos sus planos, la caracterización del 
régimen militar por su carácter ilegal e ilegítimo («gobierno elegido por nadie») y por su política de entrega del patrimonio nacional («gobierno de los monopolios»), la propuesta de enfrentamiento a dicho gobierno («a la luz o en la clandestinidad, dentro de la ley o en las catacumbas»), el posicionamiento antiimperialista y anticapitalista, la denuncia del sindicalismo vandorista y el participacionista como aliados del gobierno y traidores a los trabajadores, el llamado a la rebelión de las bases contra esa burocracia y la convocatoria a «una gran empresa común» a sectores extra sindicales como los empresarios nacionales, los pequeños comerciantes e industriales, universitarios, intelectuales, artistas, militares patriotas, estudiantes y religiosos de todas las creencias $^{16}$, fueron ejes o postulados básicos del Programa y aparecieron en forma reiterada en los diversos números del semanario.

\section{Contra el mito de la libertad de prensa}

11 En tanto vocero oficial de la nueva central obrera opuesta al régimen militar, el semanario se ubicaba como instrumento de contrainformación. Por un lado, denunciaba la persecución patronal o gubernamental, manifestada en la represión a los activistas que lo difundían y en las trabas para su distribución por el circuito de quioscos de diarios y revistas $^{17}$. Por otro, cuestionaba la escasa o nula repercusión en los medios masivos de las actividades y posicionamientos de la central obrera, o la censura y tergiversación de diversos acontecimientos ${ }^{18}$.

Una nota representativa de la posición general sobre estos temas apareció a fines de 1968. Tal vez escrita por el propio Walsh, funcionaba como balance del primer año. Allí, se ubicaba a los medios masivos formando parte «inseparable» de la estructura capitalista, en tanto "aparato» que «en su integridad pertenece al enemigo», «manipula la información» y «masifica la cultura»; se denunciaba al respecto tanto la censura oficial, como la impermeabilidad de los medios a la voz de los trabajadores:

Pueden revisarse las colecciones de los diarios sin encontrar un solo caso en que un interés obrero legítimo haya sido defendido por una empresa periodística. ${ }^{19}$

13 Estas definiciones, además de reflejar el funcionamiento de los medios masivos, forman parte de un discurso de época cada vez más generalizado en amplias franjas de productores culturales en esos años, atravesado en América Latina por la teoría de la dependencia y la denuncia de la concentración mediática. Al mismo tiempo, es evidente en estos postulados la presencia de los trabajos al respecto de una figura legendaria como Gregorio Selser, o la misma experiencia de Walsh y García Lupo en el origen de la agencia noticiosa cubana Prensa Latina, convocados por su director, el periodista argentino Jorge Ricardo Masetti, a comienzos de la década.

14 En este sentido, así como en las páginas del periódico se reiteran los cuestionamientos a la Sociedad Interamericana de Prensa (SIP) ${ }^{20}$ o, más en general, al «mito de la libertad de prensa ${ }^{21}$, en pleno desarrollo del proyecto de CGT, hacia marzo de 1969, Walsh reflexionaba sobre el boicot de la organización interamericana de los propietarios de periódicos a Prensa Latina, así como sobre el «marco idílico de la libertad de prensa», a partir de los avatares atravesados por la agencia cubana en sus orígenes ${ }^{22}$.

15 Esa doble mirada del periódico, que cuestiona por igual al régimen militar y a los propietarios de medios, trasciende las definiciones generales y es desarrollada a partir de hechos específicos. Un ejemplo significativo es la nota titulada «Los generales de radio», 
en la que a propósito del otorgamiento oficial de nuevas concesiones para la explotación de frecuencias radiales que había sido cuestionado por un sector empresarial, el semanario asume una posición de clase ${ }^{23}$.

\section{Un medio de esclarecimiento, un factor de organización}

Frente al panorama general referido, CGT rescataba la importancia de haber abierto una brecha en el sistema de medios, destacando su carácter político -que lo distancia de las publicaciones sindicales limitadas a los problemas gremiales específicos o a difundir sus servicios a los afiliados- y señalando un doble papel del periódico obrero:

Es un medio de información y esclarecimiento, pero es también y sobre todo un factor de organización ( $n^{\circ} 33$, p.1).

17 Esta definición, remite a la presencia de la concepción leninista sobre la prensa en el proyecto del semanario ${ }^{24}$, que se expresa, como veremos, en su carácter polémico, en la difusión de la línea y en la publicidad de los debates de la CGTA, en la importancia adjudicada a su distribución y en el lugar asignado a las corresponsalías.

Respecto de su «doble papel», en la tarea de (contra)información y esclarecimiento es donde se percibe cómo el Programa funciona como matriz orientadora de las principales temáticas y posicionamientos, sea en el abordaje de los conflictos gremiales a partir de los ejes allí establecidos, sea en el trabajo sobre cada uno de ellos. En su tratamiento, encontramos la utilización permanente de diversas técnicas de refutación argumental, caracterizándose su discurso por la preeminencia de los componentes didáctico y programático. En particular se disputa el sentido de diversos procesos o el significado de términos, se discuten las informaciones oficiales, se trabaja en la desmitificación, buscando desentrañar los verdaderos móviles de quienes se cuestiona.

Dos ejemplos de trabajo sobre ejes del Programa se destacan en la tarea de esclarecimiento, poniendo en juego el profesionalismo con que el grupo de periodistas asume su labor. Por un lado, las notas de García Lupo sobre monopolios, concentración económica y entrega del patrimonio nacional, que historizan diversos procesos, al tiempo que denuncian con rigurosidad los negociados de funcionarios del régimen militar vinculados a las empresas ("gobierno de los monopolios») y los confronta con los «militares patriotas»; por otro lado, las notas de Walsh que ponen en jaque a Vandor, sobre el asesinato del dirigente metalúrgico Rosendo García y de los militantes obreros Juan Zalazar y Domingo Blajaquis, ocurridos dos años antes; ese «relato peronista verdadero», como lo llamó Altamirano, cuya denuncia se encontraba en plena sintonía con el programa de la CGTA ${ }^{25}$.

Por su parte, un ejemplo paradigmático de la puesta en juego de los ejes del Programa en el abordaje de sucesos particulares, lo encontramos a propósito del conflicto petrolero en la zona de Ensenada-La Plata, de octubre-noviembre de 1968, tal vez el más importante del año. En sucesivas notas aparecidas a lo largo de dos meses, mientras los títulos configuran consignas agitativas o propagandísticas, los textos desarrollan cada uno de los ejes del Programa: se denuncia la represión oficial y el tratamiento del conflicto por los medios; se articula la información sobre la lucha gremial particular con el análisis de la política de entrega del patrimonio nacional; se contrapone la historia de las políticas petroleras antinacionales con el rescate de figuras como la del general Mosconi; se 
confronta la traición del dirigente del SUPE, Cavalli, con el coraje de los obreros y dirigentes que encabezan la lucha, así como la desatención de la CGT Azopardo, frente a la solidaridad de los petroleros de otras zonas del país y de sectores extra sindicales ${ }^{26}$.

Si bien en la cobertura de este y otros conflictos el periódico pone en juego diversos recursos expositivos (como los del denominado «nuevo periodismo») con el objetivo de atrapar la lectura, la densidad informativa que implica este tipo de abordaje, la reiteración del Programa frente a cada hecho, la insistencia en historizarlos y analizarlos en profundidad, en encontrar -aún en la derrota- «las enseñanzas de la huelga», y la consecuente exigencia o demanda hacia el lector obrero o militante, requería ser enfatizada en su coherencia con los objetivos del proyecto político-sindical. Esto último aparece de modo explícito a propósito de la publicación de un informe, elaborado por la Comisión de Asuntos o Estudios Económicos, que analiza la historia de las políticas en torno al petróleo. Allí se afirma:

Es poco lo que hemos suprimido o abreviado para esta versión periodística. Aún así, sabemos que la lectura de cifras y datos históricos resulta a veces fatigosa. Pero el semanario CGT no es ni será nunca una revista de placer o distracción sino un arma de lucha y de enseñanza. Si los trabajadores no nos acostumbramos a entender los procesos económicos, nunca sabremos realmente por qué «racionalizan» una empresa antes de entregarla al capital extranjero. Y si no entendemos esto, nunca podremos luchar con eficacia. La lectura y la divulgación de estos hechos no es una distracción sino que forma parte de la militancia obrera ( $n^{\circ} 24,10 / 10 / 1968$ : «Así se entregó el petróleo»).

Pero esta explicación, contemplada ya en el Programa ${ }^{27}$ y que era también reafirmada desde la prensa de gremios hasta allí comprometidos con el proyecto ${ }^{28}$, no necesariamente representaba al conjunto de agrupaciones sindicales que confluían en la CGTA, como se verá enseguida.

Por su parte, el carácter organizativo del periódico remite a la vinculación establecida con las regionales del interior, gremios y agrupaciones sindicales adheridas, pero también con núcleos estudiantiles, políticos y formaciones culturales. En este sentido, es en la experiencia desarrollada en torno a la distribución-difusión del periódico donde se destaca su función de organizador colectivo. Al mismo tiempo, esa experiencia -aún con sus limitaciones prácticas- permite observar una dimensión comunicacional del proyecto ${ }^{29}$, que trasciende el carácter instrumental del periódico ${ }^{30}$.

El periódico se dirigía en general a una militancia gremial y política en crecimiento. En el ámbito sindical, la distribución se orientaba, además de Capital y Gran Buenos Aires, hacia las ciudades del país donde se contaba con la adhesión de regionales de la CGT o de importantes gremios, como La Plata, Rosario, Córdoba o Tucumán, así como hacia las zonas en conflicto.

La confianza de los primeros meses en la fuerza propia -a partir de un balance que indicaba un $90 \%$ de la distribución a través de las organizaciones obreras, estudiantiles y movimientos políticos adheridos-, llevaba a comienzos de junio a plantearse objetivos de incrementar su tirada (de 30.000 a 50.000 ejemplares, según se afirmaba). Al explicitar esa búsqueda ( $\left.n^{\circ} 6,06 / 06 / 1968\right)$, se ponía en escena las dificultades existentes hasta allí (de expedición, movilidad, distribución), y se proponía a los lectores la colaboración en su resolución; un tipo de convocatoria que reaparecería en términos más dramáticos en los números de 1970, en plena etapa clandestina. 
En esta última coyuntura se explicitarían las razones políticas de los problemas de distribución. Pero ya antes, casi desde el comienzo, en agosto del 68, en una reunión del Comité Central Confederal, aún caracterizando como positiva la tarea realizada en la Secretaría de Prensa, De Luca insistía en los inconvenientes que no habían permitido alcanzar el objetivo de 50.000 ejemplares para julio. Al referirse a las fallas, cuestionaba a las «organizaciones que no lo distribuyen y regionales que apilan el periódico y no lo pagan» por no cumplir, en consecuencia, con los lineamientos de la CGT y del Congreso Normalizador ( $\left.\mathrm{n}^{\circ} 17,22 / 08 / 1968\right)$. Este tipo de cuestionamiento remite a una serie de tensiones al interior de la CGTA que pueden considerarse entre las causas del desinterés o directamente el boicot a la distribución por parte de algunas agrupaciones o gremios: principalmente, discrepancias respecto de su política; en menor medida, algún tipo de observación sobre el periódico mismo. Esto último se expresó pocos días antes de la referida convocatoria del Confederal, en una reunión de agrupaciones sindicales de base, en la que tuvieron lugar algunos diálogos «por momentos ásperos». De Luca había llamado la atención sobre la falta de cumplimiento de las agrupaciones y las organizaciones sindicales con las tareas de distribución. $\mathrm{Y}$ aunque hubo una adhesión general de los delegados presentes al semanario, el representante de la agrupación del Hielo hizo el cuestionamiento más duro:

Habría que peguntarle a los compañeros qué piensan de los trece o catorce números del diario de la CGT. Porque si el diario no se vende no es porque los compañeros no lo quieren vender. A lo mejor la gente no lo quiere comprar porque no se ve reflejada en el periódico. Todos los enemigos del pueblo salen fotografiados. No he visto una sola foto de un obrero en overol. No he visto la opinión de un auténtico obrero, cualquiera (cosa) que diga que opina él del diario. Ahí se habla de grandes problemas, grandes cosas, pero las opiniones y las inquietudes de las bases no se reflejan... Y para mí está mal hecho. La Agrupación del Hielo lo va a vender cuando sea el diario de la clase obrera argentina, y no el diario de un grupo de intelectuales que no conoce un corno de lo que pasa en las bases del movimiento obrero $\left(\mathrm{n}^{\circ} 15\right.$, 08/08/1968: «Semanario: pro y contra»).

\section{Un corresponsal en cada fábrica}

La reproducción en el semanario del cuestionamiento citado da cuenta de la problematización de su propia experiencia por el grupo de periodistas a cargo de la edición ${ }^{31}$, así como de su preocupación por lograr convertir el periódico en medio de expresión de la propuesta y las necesidades de la clase trabajadora ${ }^{32}$.

En este sentido, en el resumen de la reunión preparatoria del Confederal se insistía en que el periódico reflejaría mejor la actividad de las bases en la medida en que los mismos trabajadores cumplieran con la consigna «Un corresponsal en cada fábrica», lanzada en números anteriores. Se trataba de una propuesta de incorporar noticias sobre los conflictos gremiales elaboradas por los propios militantes sindicales, y había sido explicitada un mes antes de las discusiones citadas ( $\left.\mathrm{n}^{\circ} 12,18 / 07 / 1968\right)$ : partiendo de que los trabajadores podían y debían escribir en el semanario (iniciado por trabajadores de prensa, "pero que pertenece a la clase trabajadora»), se convocaba a escribir a los secretarios de gremios del país y a «cualquier trabajador que se sienta capaz de explicar sencilla y claramente lo que pasa en su fábrica, en su taller, en su obraje, en su ingenio», ya que resultaba imposible para el periódico enviar corresponsales a cada punto del país, 
$\mathrm{y}$ «nadie mejor que el propio trabajador conoce lo que pasa en su propio lugar de trabajo». Entonces:

La solución es que los propios trabajadores se conviertan en corresponsales del semanario CGT. De ese modo verán mejor reflejados sus problemas, podrán defender mejor sus conquistas, se sentirán más unidos en torno a una causa común.

La propuesta general se asocia, una vez más, con las ideas de Lenin de establecer corresponsalías como medio de participación directa de los militantes de base, y nos reenvía al citado rol organizativo y a la búsqueda de una relación no unívoca entre el periódico y su destinatario ${ }^{33}$. Por su parte, la idea de explicar «sencilla y claramente» lo que ocurría en los lugares de trabajo, se complementa con una observación importante: "Es posible que en algunos casos tengamos que efectuar algunas correcciones "de estilo"» 34. Esto habla del carácter profesional del proyecto del periódico, de la puesta en juego de la especificidad del trabajo periodístico en la confluencia con el movimiento obrero. $\mathrm{Y}$, al mismo tiempo, del lugar legítimo, de autenticidad otorgado al testimonio obrero-popular. Es decir, el lenguaje sencillo y claro del corresponsal obrero y las correcciones de estilo del periodista convergen en el objetivo de comunicabilidad del proyecto de la CGTA con las bases obreras y populares.

Aun cuando la propuesta de corresponsales obreros tuvo dificultades para su concreción, alcanzó un cierto desarrollo durante 1968. Entre la convocatoria explícita de julio y fines de octubre, se insistió en más de una oportunidad en ella. A comienzos de agosto se incorporaron las tres primeras colaboraciones desde centros de trabajo metalúrgicos, papeleros y textiles, señalando en su presentación el carácter político-sindical de la iniciativa: «pensamos que organizar el periodismo obrero en las bases debe ser una tarea de militancia sindical, como lo es la defensa de nuestras conquistas» $\left(n^{\circ} 14,01 / 08 / 1968\right.$ : «Los obreros escriben en su periódico»).

31 También esta iniciativa se articulaba con los ejes principales del Programa del $1^{\circ}$ de Mayo. En los días de preparación del Confederal de agosto, con cierto optimismo en que la rebelión de las bases desalojaría al vandorismo de las fábricas, el periódico incluía entre las tareas a realizar por los metalúrgicos la designación de un corresponsal obrero en cada centro de trabajo, y sostenía que daría prioridad a la información proveniente de los mismos $^{35}$.

Así como la reacción del régimen militar frente a la CGTA y el semanario -incluso mucho antes de la ofensiva represiva abierta tras el Cordobazo que lo obligaría a la clandestinidad-, se expresó en secuestros de ejemplares por funcionarios policiales en los quioscos, querellas por injurias y calumnias a sus responsables o directamente en la anulación de ediciones ${ }^{36}$, también alcanzó a los corresponsales obreros ${ }^{37}$.

\section{El «problema de la unidad», entre lo público y lo privado}

33 Las discusiones en torno del periódico y su distribución, mencionadas más arriba, aparecen en escena en el mismo momento en que se manifiestan los primeros golpes políticos hacia la CGTA. Desde su surgimiento, a pesar de su limitado peso en los grandes sindicatos de Buenos Aires, la CGTA contaba con el apoyo de las más importantes regionales del interior del país. La convocatoria a concentraciones por el $1^{\circ}$ de Mayo de 1968 había tenido buena respuesta en diversas ciudades, así como en algunos puntos del 
Gran Buenos Aires. Luego de la favorable acogida del discurso de Ongaro en Córdoba, ante 5.000 personas, el dirigente continuó visitando y llevando su mensaje a diversas provincias. A fines de mayo, Perón planteó la disolución de las 62 Organizaciones, lo que significó un golpe a Vandor y un primer gesto abierto de apoyo a la CGTA, que se fortalecería poco después, cuando en junio se difundió la carta del líder exiliado a Ongaro, brindándole su adhesión al proyecto. El apoyo de Perón resultaba por demás importante para la disputa de una serie de gremios que si bien podían padecer contradicciones objetivas con la política del régimen militar, dudaban de su distanciamiento del ala vandorista y su acercamiento a una CGTA dirigida por los sectores duros o combativos del sindicalismo peronista y que se abría, tal vez excesivamente para algunos, a sectores de la izquierda marxista, cristiana y peronista, e incluso del Partido Radical, así como a intelectuales y estudiantes ${ }^{38}$.

Si bien la convocatoria general a la unidad del movimiento constituye una constante en la correspondencia de Perón con los dirigentes sindicales y políticos, los gestos emitidos desde Madrid desde comienzos de agosto de 1968 convocando a la unidad obrera, podían leerse como una presión hacia la reunificación bajo la hegemonía vandorista, ya que a pesar del significativo peso con que contaba la CGTA en esos primeros meses de existencia, los grandes sindicatos industriales de Buenos Aires parecían todavía impermeables a su proyecto.

Esa convocatoria de Perón repercutió sobre algunos dirigentes sindicales que -como observa Brennan para el caso de gremios peronistas de Córdoba ${ }^{39}$ - «comenzaron a sospechar que su respaldo a Ongaro había sido prematuro». Esta influencia efectiva del líder del movimiento, combinada con otros factores como la presión ejercida por la dictadura o las conversaciones con el ala vandorista, cristalizaría en un duro golpe a la CGTA hacia fines de 1968, con el alejamiento de un grupo de gremios encabezado entre otros por Julio Guillán, Secretario Gremial y uno de los responsables de las relaciones con las agrupaciones y gremios. La CGTA reaccionó separando a Guillán de su Consejo Directivo el 4 de marzo de 1969, por «violar y desconocer las resoluciones del Congreso Normalizador "Amado Olmos", y del documento del 1 de Mayo de 1968» y por haber visitado regionales planteando «la disolución de las mismas para producir la unidad con el grupo vandorista $»^{40}$.

En este sentido, los problemas de distribución del semanario mencionados más arriba pueden considerarse, también, como una de las formas en que se expresaban tensiones políticas al interior del sindicalismo peronista.

El lugar ocupado por Perón en el período del exilio, las disputas por su representación en la Argentina, son conocidos. En el caso específico del semanario CGT, el viejo líder había participado de lo que tal vez en otras circunstancias se hubiese constituido en una suerte de mito de origen del proyecto periodístico. En efecto, en el verano de 1968, Ongaro lo había visitado para obtener su conformidad con los preparativos hacia el Congreso Normalizador de abril que culminaría con su consagración como Secretario General. En esa oportunidad, de modo casual, el dirigente de los gráficos conoció -a través de su anfitrión- a Walsh, que de regreso de La Habana -donde había viajado como jurado de Casa de las Américas y participado del Congreso Cultural en enero del 68-, recaló en Madrid $^{41}$. Es decir, Perón funcionó, de hecho, como articulador de una relación entre Ongaro y Walsh que de allí en más, con su reencuentro en Buenos Aires, se mostraría productiva. 
38 Tal vez por el recuerdo de ese encuentro donde presenció la bendición de Perón al proyecto de Ongaro -y, por extensión, luego, al periódico-, por estar viviendo un proceso práctico de inclusión en el peronismo ${ }^{42}$, de fuerte identificación con la experiencia político-sindical ${ }^{43}$, Walsh se enfrentó a los primeros golpes significativos contra la CGTA, hacia agosto-setiembre del 68, a la vez con bronca y desazón. El martes 17 de setiembre describe en su diario el desaliento que percibió en una reunión de secretarios generales de gremios: «un desaliento que todos tratan de capear con fórmulas, como hermanos que se consolaran de cierta enfermedad de la madre, todavía no mortal». La reunión le produjo «congoja», sensación de «derrota»: «No había nadie que galvanizara esa reunión, que con Ongaro habría sido otra cosa», afirma. Pero Ongaro, recuerda, estaba en España, «tratando de convencer a Perón».

Dos días más tarde, Walsh se refiere también en su diario a conversaciones en la casa de John W. Cooke, donde se encuentra con otros compañeros a propósito de la muerte de éste:

Tristán, el viejo reorganizador de la juventud, diciéndome, «Pero Ongaro tendrá que acatar la conducción». [...]

La idea general que privaba en el discurso de Garzón es que el Viejo [Perón] moviliza al Lobo [Vandor] para obstruir la CGT colaboracionista [Coria, Taccone, etc.], a cambio de permitirle conservar el gremio; que de ese modo la unidad se convierte en una exigencia, aun a costa de Ongaro; que por otro lado, mete a todos los políticos en una bolsa para poder manejarlos solo. Etcétera. La rabia intensa que todo este «tacticaje» me provoca; el deseo de que Raimundo les patee el tablero una vez más. ${ }^{44}$

La rabia frente al «tacticaje», la esperanza en Raimundo, esa «repentina certeza de que lo duro del camino es lo que justifica la inflexibilidad total de los principios» (martes 17/9/1968), parecen traducirse en la primera página del número 21 de CGT (aparecido el jueves 19/09/1968). Bajo el título "Condiciones para la unidad», ilustrada con la foto de Ongaro, una nota a modo de editorial insiste en la discusión reabierta con las presiones hacia la reunificación sindical. Allí se vuelve sobre el sentido asignado por cada uno a la unidad, cuestión trabajada en otras notas, y se reafirman al respecto los «principios» del Programa del $1^{\circ}$ de Mayo: "La Unidad que tiene su origen en las Bases y su fuente de acción en el Programa; que sólo excluye a traidores y delincuentes; que se expresa en lucha abierta contra el sistema: esa es la única Unidad que acepta la CGT de los Argentinos». De algún modo, lo que afirmaba en su diario en esos mismos días: el deseo que Ongaro les patee el tablero.

41 En los meses sucesivos, la citada huelga petrolera y algunas luchas o planes de acción del interior del país, mantuvieron la presencia de la CGTA en la escena política. Sin embargo, ya para fines de ese año, diversos sucesos configuraban una situación de debilitamiento que se extendería a comienzos de 1969: la derrota en el conflicto petrolero, y otros menores; el incremento de las presiones por la reunificación y el distanciamiento de algunos gremios; probablemente, también, la muerte de Cooke, en tanto referente combativo, y el fracaso del foco guerrillero de Taco Ralo en setiembre. Ese clima de fines del 68 se refleja en los escritos personales de Walsh, donde además de afirmar que se encuentra «cansado y derrotado», sostiene (19/12/1968):

La rebelión de las bases quedó en los papeles. Las bases no tuvieron expresión real, no se integraron orgánicamente en la CGT. De ella no surgieron dirigentes, activistas, cuadros. De este modo, por cierto, los movimientos de protesta fracasaron. La CGT fue quedando cada vez más desnuda frente al enemigo, y el 
gobierno no tuvo necesidad de intervenirla. La maniobra de unidad promovida por

Perón le asestó un golpe decisivo.

\section{Hacia la clandestinidad} incrementada por el desgaste de la larga huelga de los gráficos contra Fabril Financiera, una vez más frente a la racionalización empresaria. Poco después, días antes del Cordobazo, reaparecían en el periódico los problemas de distribución, ahora en relación con el circuito de quioscos. Iniciadas ya las protestas que desencadenarían el levantamiento popular de fines de mayo, se publica en tapa una denuncia de las presiones del gobierno y la «mafia» de los distribuidores de diarios, que habían impedido la llegada del número 43 a los quioscos. Caracterizando la situación como "grave», CGT convocaba: «Compañero: De Usted Depende que el Próximo Número de CGT aparezca el 22 de Mayo. Retire Ejemplares y colabore en su Venta» ( $n^{\circ} 44,08 / 05 / 1969$ y n $\left.{ }^{\circ} 45,22 / 05 / 1969\right)$.

A partir del periódico siguiente $\left(n^{\circ} 46,05 / 06 / 1969\right)$ y hasta el último legal ( $n^{\circ} 49$, 25/07/1969), estos problemas quedarían desplazados por los sucesos de mayo en el interior del país.

Sin duda, el Cordobazo y otros levantamientos del interior revitalizaron a la CGTA y su Programa. Sin embargo, esto duró poco tiempo, ya que el gobierno aprovechó el asesinato de Vandor para generalizar la represión, las intervenciones a los gremios y el encarcelamiento de sus principales dirigentes. Frente a la abierta persecución desatada, el 30 de junio se decide el pase a la clandestinidad. Con ello, la periodicidad cambia de quincenal a mensual, deja el color azul que usaba para recuadros o para su nombre y sigue saliendo sólo en blanco y negro, mantiene su formato dos números más pero ya para octubre se reduce a la mitad, al igual que el número de páginas.

El 4 de agosto se hizo efectiva la prohibición oficial de CGT. Ante esto, en los números de setiembre y octubre se insistía en la necesidad de mantener la prensa clandestina, que tenía un lugar destacado entre las cinco consignas básicas para esta etapa: Organización y Disciplina, Seguridad, Trabajo en Fábrica, Agitación y Propaganda, Solidaridad ( ${ }^{\circ} 52$, 10/10/1969).

Pero a pesar de la voluntad y dignidad demostrada en esas circunstancias, las dificultades se incrementaron en forma notable ${ }^{46}$. En el número de noviembre, encontramos un artículo, «Las cosas claras», centrado en los problemas de la etapa clandestina. Aun cuando se manifiesta cierta cuota de optimismo, reaparece la referencia a la imposibilidad de enviar el periódico por las vías legales. En esa línea, el número 55 de febrero de 1970 reflejaba el marcado debilitamiento a que había llevado la clandestinidad, e insistía en toda la problemática que se venía denunciando desde su ingreso a esta etapa, o aún desde antes: problemas de edición e impresión, distribución, financiamiento. En un último intento de supervivencia, se establecían objetivos ambiciosos: duplicar la frecuencia de aparición («dos ediciones mensuales en vez de una») y triplicar su circulación. Asimismo, reaparecía el problema de la distribución, ahora abiertamente asociado a las diferencias políticas, pasadas y presentes:

Es incorrecto, en cambio, y deshonesto, que quienes en nada contribuyen a la aparición del periódico, se permitan el lujo de censurarlo, difamarlo y hasta recomendar en los círculos de su influencia que no sea distribuido. Cada vez que esto sucedió en el pasado, los difamadores no tardaron en pasarse a la vereda de 
enfrente, demostrando así que sus diferencias reales no eran con el periódico, sino con la línea y el programa de la CGT de los Argentinos, que el periódico representa ( $n^{\circ}$ 55, febrero 1970).

Este número es el último editado por el equipo de periodistas nucleado en torno a Walsh. Pocos meses después, en julio de 1970, a poco más de dos años del Congreso «Amado Olmos», se concretaba la tan mentada «reunificación» en el Congreso Normalizador «Augusto T. Vandor», donde sería electo secretario general José Ignacio Rucci. A partir de este Congreso del 70, o tal vez ya desde antes, la CGTA dejaría de constituir una central obrera alternativa para convertirse en una corriente político sindical que -aun con sus limitaciones- desarrollaría un papel no menor en la promoción de las tendencias revolucionarias del Peronismo.

También en lo referido a la relación y posicionamientos de estas tendencias respecto de Perón y el Movimiento, los escritos personales de Walsh traslucen inquietudes tempranas. Es decir, los citados cuestionamientos al «tacticaje» o «la maniobra de unidad promovida por Perón», como vimos, formaron parte de conversaciones privadas o quedaron registrados en su diario, pero no se expresaron de modo explícito en el semanario CGT, donde de algún modo se tradujeron en la discusión sobre el problema de la unidad. En el mismo sentido, es interesante recuperar unas líneas más del diario personal -justamente de los mismos días de edición del último número de CGT bajo su dirección (febrero de 1970)-, donde Walsh daba cuenta de una conversación singular. A través de la misma, se instala un problema directamente asociado a su visión de Perón, así como al futuro inmediato de la izquierda peronista en la que el escritor había comenzado a militar de modo cada vez más orgánico:

(Germán Rozenmacher) quiere hablar conmigo, hoy no porque tiene que terminar un trabajo. La cara le vacila, menciona la palabra "política», parece que quisiera sincerarse. Con Tito (Cossa), Somigliana y Talesnik están escribiendo una obra de teatro sobre el peronismo ${ }^{47}$. Al principio pensaron en sketches separados, pero después la obra adquirió continuidad, integridad. Él escribió una parte en que un comisario peronista le dice a un militante peronista antes de torturarlo: «Vos sos peronista, yo también soy peronista. Vos tenés una carta de Perón, yo tengo otra carta de Perón. Vas a morir por zonzo», y le da a la picana.

Mi presencia tal vez intranquiliza a Germán. Hago lo posible por tranquilizarlo. Le digo que yo también tengo un cuento empezado, que se llama «El Hombre», donde digo cosas como ésas. Pero que no me decido a terminarlo, publicarlo.

Entonces se anima:

-Esas cosas hay que empezar a decirlas -dictamina.

\section{Final}

Como señalé en otro lugar ${ }^{48}$, si bien el Cordobazo de mayo de 1969 puede considerarse una suerte de hito que reorienta o generaliza la mirada y la intervención de intelectuales o trabajadores de la cultura hacia una articulación práctica con el movimiento obrero y la protesta social, ya desde un año antes periodistas, artistas plásticos, cineastas, poetas o profesionales de distintas disciplinas habían encontrado un espacio de confluencia en torno a la CGT de los Argentinos. La amplitud, riqueza y diversidad de ese proceso, contempla la elaboración del diseño general de las páginas del periódico por artistas/ publicistas sobre la mesa de una suite del Hotel Alvear Palace ${ }^{49}$, la colaboración de Ricardo Carpani -tal vez el mayor representante del arte político vinculado a la lucha sindical a lo largo de esa década ${ }^{50}-$, y acciones de formaciones emergentes como los artistas de 
vanguardia que realizaron en noviembre del 68 las muestras de la obra Tucumán Arde en las sedes de la CGTA de Rosario y Buenos Aires ${ }^{51}$, o el grupo Cine Liberación que realizó en el verano de 1969 un noticiero cinematográfico, de corta vida, para la central obrera ${ }^{52}$. También la colaboración de tantos otros participantes de las «comisiones de trabajo» referidas.

Es decir, los dos años en que Walsh preparó y dirigió el semanario CGT (inicios 1968inicios 1970) condensan un tipo de relación de esos sectores de la «cultura» con el movimiento obrero que -aun cuando pueda tener antecedentes en la historia argentinaresulta paradigmático. Un elemento que desde mi punto de vista singulariza la búsqueda de varios de ellos -y los distingue de otros que también recorren, antes o después, el camino del «compromiso» intelectual- es que esa vivencia de algún modo les permite o les demanda reformular sus lenguajes y creaciones para incorporar en ellas el mundo obrero y popular al que al mismo tiempo ahora aspiran a dirigirse. Las inquietudes de Walsh, citadas al comienzo, respecto de cómo recuperar para la Novela su propia experiencia en torno a la CGTA o hechos como el Cordobazo y el Rosariazo, no son ajenas a las preguntas que se hacen muchos de los protagonistas de esas otras formaciones culturales mencionadas. Al igual que para Walsh, también esos levantamientos populares y otros hechos (Tucumán para los plásticos de vanguardia; la Resistencia Peronista para Cine Liberación, etc.) proveían nuevos «centros de verdad» para incorporar a sus obras, por un lado, y a los cuales ellos mismos podían sumarse, por otro. Durante 1968 y 1969, el espacio de la CGT de los Argentinos puede pensarse como un laboratorio -seguramente precario y fugaz- para esas búsquedas políticas, culturales, intelectuales. Walsh tuvo mucho que ver al respecto.

\section{NOTAS}

1. Este artículo es un reordenamiento parcial (y en menor medida reescritura) del publicado originalmente con el título «Semanario CGT. Rodolfo Walsh: periodismo y clase obrera», Revista Causas y Azares. Los lenguajes de la comunicación y la cultura en (la) crisis: Buenos Aires, $\mathrm{n}^{\circ}$ 6, 1997. Desde esa primera versión en adelante, fueron publicados muchos libros y artículos sobre Walsh (y en especial este período de fines de los años sesentas) que aunque aquí no incorporados resultan sin duda de mucho interés.

2. Walsh retoma el proyecto de la novela a comienzos de 1977. Su último cuento, "Juan se iba por el río", había sido proyectado como el primer capítulo de aquella (Ver Víctor Pesce, «Rodolfo Jorge Walsh, el problemático ejercicio del relato», Nuevo Texto Crítico, $\mathrm{n}^{\circ}$ 12-13, julio 1993-junio 1994. En particular p. 49 y sgtes. Allí se cita el testimonio de Lilia Ferreyra, su compañera desde 1967, aparecido en Controversia, nº 4, México, 1980).

3. ¿Quién mató a Rosendo? sería editado ese mismo año por Tiempo Contemporáneo. Pero Walsh prologaría para Jorge Álvarez la reedición del libro de Jorge Ricardo Masetti Los que luchan y los que lloran, también editado en 1969.

4. Rodolfo Walsh, Ese hombre y otros papeles personales, Buenos Aires: Seix Barral, 1996. pp. 99-102. 
5. Una cuestión que de todos modos Walsh se preocupa por tematizar en privado y públicamente. A partir de entrevistas realizadas y de la publicación de sus papeles personales (Rodolfo Walsh, op. cit.) podemos rastrear estos elementos en su reflexión cotidiana. Respecto de la tematización pública del problema del compromiso intelectual o de la relación arte-política, véase el reportaje de Ricardo Piglia, de marzo de 1970, publicado en Un oscuro día de justicia, Buenos Aires: Siglo XXI, 1973.

6. A mediados de 1969 , sostiene en una entrevista que de ninguna manera ha renunciado a la literatura (en Siete Días, n 110, Buenos Aires, 16-06-1969). Sobre la tensión entre ambos proyectos, ver en general sus escritos desde 1968 en adelante, en R. Walsh, op. cit. 7. Ver op. cit., p. $92(31 / 12 / 68)$.

8. Op. cit., pp. 114-115 (06/06/69).

9. Reportaje de Ricardo Piglia (marzo, 1970), op. cit.

10. En adelante cuando se trate de textos correspondientes al Semanario CGT se incluirá su número y fecha entre paréntesis.

11. Beba C. Balvé, y Beatriz S. Balvé, El '69. Huelga política de masas. Rosariazo-CordobazoRosariazo, Buenos Aires: Contrapunto, 1989, pp. 178-179.

12. A fines de abril, nueve regionales de la CGT habían adherido a la CGTA, entre ellas las principales del interior del país. En mayo lo hizo Córdoba.

13. La mayor parte de sus números fueron de entre 4 y 8 páginas, mantuvieron un formato «sábana» $(42 \mathrm{~cm}$. x $58 \mathrm{~cm}$.) y eran armados en el propio taller de los gráficos en base a un esquema general de diagramación, de páginas a seis columnas. Pueden consultarse en: http://www.cgtargentinos.org/

Desde marzo de 1970 seguiría publicándose esporádicamente hasta 1973, un periódico con un diseño y formato (reducidos) similar al de los números del período de clandestinidad, aunque ya no por el mismo grupo de redactores bajo la dirección de Walsh. Es probable que su director en este segundo período haya sido Quito Burgos. El número 56 es de marzo de 1970 y el 69, de abril de 1973. Este es el último que pude consultar gracias a la gentileza de Eduardo Jozami, quien me los facilitó. Pero se habría editado un número más. 14. Véase Carlos Mangone y Jorge Warley, El manifiesto. Un género entre el arte y la política, Buenos Aires: Biblos, 1994.

15. La idea del programa como «matriz textual de la totalidad del periódico» fue sugerida por Bárbara Crespo (Entrevista con el autor, 1990). Ver también B. Crespo, «Semanario CGT», Buenos Aires, Mimeo, 8 págs. Allí se detiene en la presencia del género entrevista en el periódico.

16. En particular, el periódico abrió sus páginas a dos fuerzas importantes en el enfrentamiento al gobierno: el movimiento estudiantil -que por ejemplo en Tucumán llegó a integrarse al Consejo Directivo- y el Movimiento de Sacerdotes para el Tercer Mundo, constituido en Córdoba, también en mayo de 1968.

17. Véase respectivamente, $n^{\circ} 20,12 / 09 / 1968$ («Les duele») y $n^{\circ} 12,18 / 07 / 1968$ («Heroico operativo policial»); y en particular $n^{\circ} 44,08 / 05 / 1969, y$ 45, 22/05/1969 («Por qué no estamos en la calle»).

18. «Tres focos de televisión, que en seguida se apagaron, y dos cronistas aislados cubrieron en la noche del 16 de agosto la más importante asamblea obrera que se haya realizado en el país después del Congreso Normalizador de marzo. Al día siguiente no había diarios y lo que pudiera pasar en la reunión del Comité Central Confederal de la CGT se daba ya por viejo en el mercado de las noticias» $\left(n^{\circ} 17,22 / 08 / 1968\right)$. Ver también $n^{\circ} 5$, 30/05/1968 («Ongaro»); n 6, 06/06/1968 («Habla Ongaro»); n 10, 04/07/1968 («La verdad 
sobre los actos en todo el país»); n² 24, 10-10-1968 («Algo sobre guerrilleros»); $n^{\circ} 26$, 24-10-1968 («SIP...» y «Crónica de la tortura y de la victoria»); $n^{\circ}$ 27, 31/10/1968 («El caso...»); $n^{\circ}$ 50, 23/08/1969 («Las cosas claras»).

19. $\mathrm{N}^{\circ} 33$ (12/12/1968): «Un millón de ejemplares. 33 semanas junto al pueblo».

20. $\mathrm{N}^{\circ} 26,24 / 10 / 1968$ («SIP: amos de la prensa con anticonceptivos»).

21. $N^{\circ} 10,04 / 07 / 1968 ; n^{\circ} 44,08 / 05 / 1969 ; n^{\circ} 45,22 / 05 / 1969$.

22. Rodolfo Walsh, «Prólogo», Jorge R. Masetti, Los que luchan y los que lloran, Buenos Aires: Jorge Álvarez, 1969. Se trata de una reedición que incorpora el prólogo de Walsh. La primera edición del texto de Masetti es de 1958 (Buenos Aires: Freeland) y lleva por subtítulo «El Fidel Castro que yo vi».

23. «La nueva distribución de las concesiones para operar radioemisoras en todo el país ha servido para desencadenar una crisis militar, pero tanto la crisis misma, como el escándalo desatado en torno del tema, parece que no servirán para que la opinión púbica sepa realmente de qué se trata. Los antiguos concesionarios han elegido como campo de batalla para defenderse dos hechos ligados entre sí: que abundan los generales y los almirantes entre los nuevos concesionarios, y que éstos, sumados a los parientes y amigos de los gobernantes, constituyen una red de intereses vinculados al gobierno militar. Haber elegido este costado del asunto ha sido, aparentemente, un error, pues los oficialistas han devuelto con efecto de boomerang las acusaciones, nombrando los generales y los parientes y amigos que, hace diez años, sirvieron de escalera a los concesionarios que ahora cesarán. Sin embargo, la verdad profunda es otra. Los concesionarios de hace diez años, y los de ahora, se aprovechan del mismo sistema de explotación de la radiodifusión con propósitos particulares» ( $\left.n^{\circ} 18,29 / 08 / 1968\right)$.

24. «El periódico no es sólo un propagandista y un agitador colectivo, sino también un organizador colectivo», sostiene Lenin en ¿Qué hacer? Según más de un testimonio, en esos días Walsh revisaba los escritos de Lenin sobre la prensa, a los que se refería con frecuencia. Horacio Verbitsky, op. cit; Eduardo Jozami, entrevista con el autor, Buenos Aires, 1992. Por su parte, Bárbara Crespo también observó la presencia del leninismo en su estudio sobre CGT (op. cit.).

25. En ambos casos se trata de unas de las pocas notas firmadas del semanario. Respecto de García Lupo, ver no 15 (08/08/1968: «Los generales monopolistas»), nº 21 (19/09/1968: «Lo que pensaba el general Savio de nuestro acero»), $n^{\circ} 24$ (10/10/1968: «Lo que pensaba el general Mosconi de nuestro petróleo»), n 27 (31/10/1968: «Radiografía de la familia Lanusse»). Varias otras notas sobre estos temas, sin firma, corresponden a este periodista, por ejemplo, las compiladas en: Contra la ocupación extranjera, Buenos Aires: Sudestada, noviembre de 1968. Sobre el libro de Walsh, véase: Carlos Altamirano, «El peronismo verdadero», Punto de vista, $n^{\circ} 43$, agosto de 1992. Sobre el período: Daniel James, Resistencia e integración. El peronismo y la clase trabajadora argentina, 1946-1976, Buenos Aires:

Sudamericana, 1990.

26. El periódico abordó el conflicto entre el n 23, 03/10/1968 y el n³2, 05/12/1968. 27. «La lucha contra el poder de los monopolios y contra toda forma de penetración extranjera es misión natural de la clase obrera, que ella no puede declinar. La denuncia de esa penetración y la resistencia a la entrega de las empresas nacionales de capital privado o estatal son hoy las formas concretas del enfrentamiento».

28. Dice El Telefónico: «Los trabajadores debemos felicitarnos de contar con un órgano periodístico que logró explicar los “temas prohibidos”, de la manera más sencilla. Eso, unido a una investigación rigurosa y responsable, ha hecho posible la publicación de una serie de notas, en la que con datos, cifras, nombres, fechas, se pone en descubierto la 
clave del manejo de la economía nacional» (Citado en $\mathrm{n}^{\circ}$ 28, 07/11/1968: «Semanario CGT: verdades para todos»).

29. «"La propia difusión del periódico empezará por crear automáticamente un lazo efectivo" (Lenin). Las relaciones entre una y otra localidad van adquiriendo regularidad, asegurando así no solamente la difusión del periódico, sino también -y esto es mucho más importante todavía- el intercambio de experiencias, de documentación, de fuerzas y recursos» (Worontzoff, Madeleine: La concepción de la prensa en Lenin, Barcelona: Fontamara, 1979; pág. 35). De cualquier modo es importante diferenciar el lugar central del periódico en la organización del Partido en Lenin, en el momento del ¿Qué hacer? (1901-1902), del lugar preponderante en lo organizativo de la propia estructura de la CGTA, en particular en el período previo a la etapa clandestina, es decir, hasta mediados de 1969.

30. Sostenía Ricardo De Luca: «Tenemos un periódico que es la herramienta necesaria para que la política de la CGT penetre en la conciencia de los trabajadores» ( $\mathrm{n}^{\circ} 17$, 22/08/1968).

31. Respecto del trabajo de Walsh en un momento previo de la experiencia, cuando la elaboración inicial del Programa del $1^{2}$ de Mayo, recuerda Lilia Ferreyra (participante del equipo de periodistas y compañera del escritor): «Tiene que ver con una actitud del intelectual, por un lado, y con el oficio del periodista. Él ponía el grabador, ponía la oreja para tomar nota. Era tremendamente respetuoso, no se ponía a discutir como un dirigente político. Entendía que en ese momento podía aportar desde su oficio. Por supuesto, no era un hombre inocente desde el punto de vista de tendencias o concepciones políticas. Lo que él hace es redactar, hace una síntesis de todas las cosas que se planteaban. Lo que está planteado en el Programa del $1^{\circ} \mathrm{de}$ Mayo fue hecho por Ongaro y por los otros compañeros dirigentes que participaban de esos plenarios. Luego de la transcripción de todo ese material, Rodolfo le dio la forma. Incluso, después de la primera versión fue discutido y analizado. Ongaro le corrige cosas, como que Rodolfo había puesto clase obrera y él le dice que ellos dicen clase trabajadora porque englobaba más de lo que serían los obreros industriales. Con esas acotaciones, Rodolfo iba asimilando rápidamente lo que era toda esa corriente y su concepción política». Entrevista con el autor, 20/10/1992.

32. Presentando los comentarios de la revista de telefónicos citada más arriba, CGT sostenía: «Con la misma honestidad con que publicamos las objeciones, hoy vamos a copiar palabras elogiosas aparecidas en la revista El Telefónico. Unos y otras nos alegran porque muestran que el Semanario CGT es leído y discutido por sus destinatarios naturales. Unos están de acuerdo, otros no, pero todos lo tienen en cuenta. Pobres de nosotros cuando nadie tenga nada que criticar, ese día nos sentiríamos muertos, porque lo peor que podría pasar es que nadie discutiera nada. Preferimos la polémica antes que la paz del cementerio». ( $\left.n^{\circ} 28,07 / 11 / 1968\right)$.

33. Sobre el lugar de las corresponsalías en Lenin ver Worontzoff, op. cit., pp. 53-56.

34. Al respecto, recuerda Verbitsky: «En el resto del periódico se publican los informes preparados por los corresponsales populares de todo el país, que la redacción profesional reescribía, tratando de no quitarles en el proceso de edición la autenticidad del testimonio militante». Op. cit.

35. №16 (15/08/1968): «Vandor. Qué deben hacer los metalúrgicos». También en relación con el objetivo de vinculación del periódico con los conflictos, a fines de agosto se incorporó, esta vez en primera página, una nota enviada por un corresponsal desde la flota petrolera ( $n^{\circ} 26,24 / 08 / 1968$ : «Mendoza: paran los petroleros»). 
36. Sólo tomando el mes de julio del 68, encontramos estos tres tipos de represalias: la intimidación de los vendedores de diarios con el secuestro de ejemplares $\left(n^{\circ} 12\right.$, 18/07/1968), una querella contra el Secretario de Prensa, Ricardo De Luca ( $n^{\circ} 13$, 25/07/1968) y la anulación de la primera edición del nº 11 (11-07-1968).

37. Es el caso de un trabajador de la construcción que -tras publicar una denuncia firmada contra el Secretario General del gremio, el dirigente participacionista Rogelio Coria- fue despedido de la obra en que trabajaba y, en otro episodio independiente pero «agravado» por ser corresponsal de CGT, fue detenido y torturado. Ver $n^{\circ} 15$ (08/08/1968): «Coria: sin maquillaje»; y n 19 (05/09/1968): «Coria lo hace echar, la policía lo tortura». 38. Recuérdese que fue acusada de ser la «CGT de los estudiantes» ( $n^{\circ} 27,31 / 10 / 1968$ : «Aclara Ongaro»).

39. James P. Brennan, El Cordobazo. Las guerras obreras en Córdoba. 1955-1976, Buenos Aires: Sudamericana, 1996.

40. $\mathrm{N}^{\circ}$ 41, 27/03/1969: «Guillán fue separado».

41. Este encuentro fue relatado más de una vez por Horacio Verbitsky, op. cit., entre otros.

42. Walsh afirma en una entrevista de 1972: «Mi encuadramiento dentro de una organización peronista ha sido en la CGTA». (Primera Plana, 13/06/1972).

43. Escribe el 17/09/1968: «Me fui lleno de congoja, pensando -como otras veces- que estamos derrotados. Pero yo hace poco que ando con ellos, y es la primera vez que escribo espontáneamente la palabra "estamos" ». Rodolfo Walsh, Ese hombre, op. cit., p. 83.

44. Las aclaraciones entre corchetes son mías.

45. En setiembre de ese año, Walsh destaca la fe y aptitud de Ongaro en esos días (Véase Prólogo a Ongaro dice..., Buenos Aires: Soberanía Popular de la CGTA, noviembre de 1969). 46. Junto al encarcelamiento de Ongaro y otros miembros del Consejo Directivo, el propio Walsh debió abandonar su casa frente al riesgo de ser detenido. Recuérdese que pocos días antes del asesinato de Vandor, había publicado como texto de non-fiction su investigación sobre el asesinato de Rosendo García. En ese marco, los últimos números de ese año se realizaron en forma clandestina, en una imprenta vieja, pues ya no se podían utilizar las instalaciones de los gráficos. Esto redujo también la tirada.

47. Se refiere a «El avión negro», estrenada ese año.

48. Mariano Mestman, «Consideraciones sobre la confluencia de núcleos intelectuales y sectores del movimiento obrero. 1968-1969», AA.VV., Cultura y política en los años 60, Buenos Aires: CBC, 1997.

49. Testimonio de Oscar Smoje al autor, Buenos Aires, 1993. Él y Jorge Sarudiansky, que trabajaban en una agencia cuyo estudio estaba en el hotel referido, elaboraron un diseño de página y criterios generales para la diagramación del periódico que se mantuvieron hasta el inicio de la etapa clandestina, abierta con su prohibición oficial. A partir de ese primer diseño, era en general Horacio Verbitsky quien se encargaba del control del armado de cada número en el taller. Al respecto ver Horacio Verbitsky, «Nacer en Madrid», íbid.

50. Además de ilustrar algún número del periódico y varias publicaciones del gremio gráfico dirigido por Ongaro, Carpani tuvo a su cargo la presentación «política» de un libro que compilaba documentos de la CGTA del período 1968-1973, entre otras actividades.

51. Recuperadas por el propio semanario CGT: $n^{\circ} 31(28 / 11 / 1968)$ y $n^{\circ} 33(12 / 12 / 1968)$. Walsh que firma un documento junto a ellos y otros intelectuales en mayo de 1968, cuando una zona de la vanguardia porteña «rompe» con el Instituto Di Tella-, de alguna manera fue el articulador de la relación con la central obrera opositora. 
52. Al mismo tiempo, la militancia nucleada en torno a la CGTA funcionó como uno de los núcleos promotores de la exhibición clandestina de «La hora de los hornos» desde fines de 1968. Walsh participó en una de sus primeras proyecciones antes de iniciar ese proceso, y consideraba el film un camino posible para recuperar la revolución desde el arte: «una ruta que yo empecé a transitar hace diez años», afirmaba respecto del carácter documental/testimonial del film y en alusión a «Operación Masacre». Rodolfo Walsh, op. cit., pp. 92, 95).

\section{RESÚMENES}

El artículo analiza la experiencia de Rodolfo Walsh en torno al Semanario CGT (1968-1969) -que dirigió para la CGT de los Argentinos entre mayo de 1968 y febrero de 1969, durante los años de enfrentamiento al régimen militar del general Juan Carlos Onganía-, así como la repercusión que tuvo en su camino literario y creativo. En el marco de una confluencia más amplia de profesionales, intelectuales y trabajadores de la cultura con esta nueva central obrera, el texto focaliza en cómo Walsh y el grupo de periodistas problematizaron los alcances y límites del periódico en su comunicación con estos sectores de la clase trabajadora argentina. A partir de esta y otras experiencias en torno a la CGT de los Argentinos (estudiadas por el autor en otros trabajos), se propone pensar un escenario en torno a 1968/1969, configurado como un precario y fugaz laboratorio donde se cruzan sectores medios con sectores obreros en sus búsquedas políticas, culturales e intelectuales.

L'article analyse l'expérience de Rodolfo Walsh dans l'hebdomadaire Semanario CGT (1968-1969) qu'il a dirigé pour la Confédération General du Travail des Argentins entre mai 1968 et février 1969, pendant les années d'affrontement au régime militaire du général Juan Carlos Onganía. Il étudie également la répercussion de cette expérience dans le parcours littéraire et créateur de Walsh. Dans le contexte de la plus ample confluence de professionnels, d'intellectuels et de travailleurs de la culture avec cette nouvelle centrale ouvrière, le texte focalise son attention sur les limites qui a trouvé l'hebdomadaire dans sa communication avec la classe ouvrière argentine. À partir de cela et d'autres expériences - que l'auteur a étudiées ailleurs - il se propose de penser la CGT des Argentins comme un «laboratoire » fugace et précaire, où des secteurs de la classe moyenne se croisent avec des secteurs ouvriers dans leurs recherches politiques, culturelles et intellectuelles.

The article analyzes the experience of Rodolfo Walsh as the editor of CGT (1968-1969), the weekly newspaper of the Confederación General del Trabajo de los Argentinos, one of the Argentina's largest trade union federation of that period. Walsh's editorship coincided with the military dictatorship of General Juan Carlos Onganía and the essay focuses on the repercussions this experience had on Walsh's literary work and political activism. Walsh and the group of journalists entrusted with putting out the weekly strived to effectively engage the working class, as did other professionals, artists and intellectuals who coalesced around the trade union federation around this period. This essay proposes thinking about the federation during these particular year (1968-1969) as a precarious experiment where middle-class sectors fleetingly coincided with the working class in their political, cultural and intellectual quests. 
ÍNDICE

Mots-clés: Semanario CGT, Walsh, Ongaro, CGT de los Argentinos, Cordobazo, 1968

Palabras claves: Semanario CGT, Walsh, Ongaro, CGT de los Argentinos, Cordobazo, 1968

Keywords: Semanario CGT, Walsh, Ongaro, CGT de los Argentinos Cordobazo, 1968

\section{AUTOR}

MARIANO MESTMAN

UBA-CONICET, Argentina 